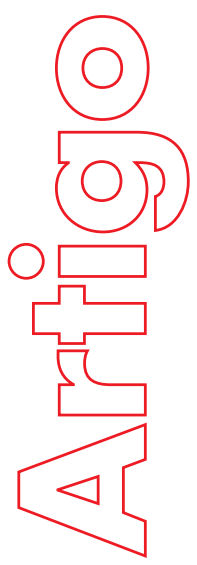

\title{
BRASÍLIA E O SEU PLANEJAMENTO TERRITORIAL: NOVAS ESCALAS, NOVAS DEMANDAS E NOVOS PARADIGMAS
}

\author{
Ricardo Farret
}

p. $01-17$

\section{Revista}

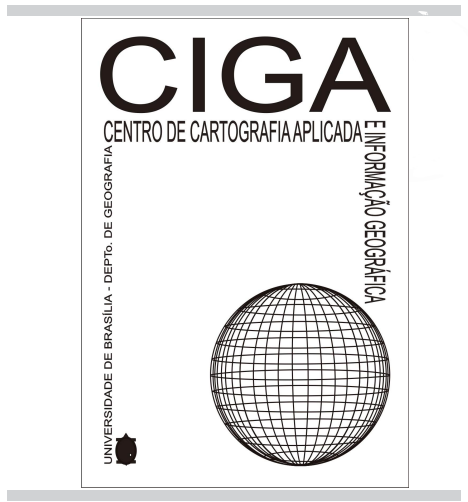

Revista Eletrônica:

Tempo - Técnica - Território, V.7, N.2 (2016), 1:17 ISSN: 2177-4366

DOI: https:// doi.org/10.26512/ ciga.v7i2.19093
Como citar este ar tigo:

RICARDO, F. BRASÍLIA E O SEU PLANEJAMENTO TERRITORIAL: NOVAS ESCALAS, NOVAS DEMANDAS E NOVOS PARADIGMAS. Revista Eletrônica: Tempo Técnica - Território, v.7, n.2 (2016), p. 1:17

ISSN: 2177-4366. DOI: https://doi.org/10.26512/ciga.v7i2.19093

Disponível em:

http://periodicos.unb.br/index.php/ciga

Este obra está licenciado com uma Licença Creative Commons Atribuição-NãoComercial 4.0 Internacional. 


\section{BRASÍLIA E O SEU PLANEJAMENTO TERRITORIAL: NOVAS ESCALAS, NOVAS DEMANDAS E NOVOS PARADIGMAS}

\section{Ricardo Farret}

Arquiteto e Urbanista, PhD em Planejamento Urbano e Regional, Professor Aposentado da Faculdade de Arquitetura e Urbanismo, atualmente é Pesquisador Associado do Núcleo de Estudos Urbanos e Regionais (NEUR), ambos da Universidade de Brasília.

E-mail: farret@unb.br

RESUMO : Construída a partir de um plano urbanístico básico, Brasília, a capital federal do Brasil, inaugurada em 1960, com o seu rápido crescimento populacional e ocupação territorial, vê o surgimento precoce de uma não planejada estruturação metropolitana. Somente a partir dos anos 1970, ainda que de forma descontínua, implanta-se o planejamento de seu território às escalas macro: do Distrito Federal, da Área Metropolitana e da Região Geoeconômica. Neste artigo busca-se descrever, de forma resumida, os diversos planos e projetos de organização territorial que, desde então, são formulados para o Distrito Federal e seu entorno.

PALAVRAS-CHAVE: Brasília; Planejamento Territorial; Projetos Urbanos

ABSTRACT: Built a partir of a urbanistic basic plan, Brasília, the federal capital of Brazil, dedicated in 1960, with its rapid population growth and spatial occupation, sees the precocious emergence of a non-planned metropolitan structure. Only after the 1970s, even in a descontinuous way, is formulated various macro scales attempts to spatial planning: of the Federal District, of the Metropolitan Area, and of the Geoeconomic Region. In this article, the various spatial plans and projects proposed for the Federal District and its surrounding área are described in a resumed form.

KEY WORDS: Brasília; Spatial Planning; Urban Projects

Resumen: Construida a partir de un plano urbanístico básico, Brasilia, la capital federal de Brasil, inaugurada en 1960, con su rápido crecimiento poblacional y ocupación territorial, ve el surgimiento precoz de una no planificada estructura metropolitana. Sólo a partir de los años 1970, aunque de forma discontinua, se implanta la planificación de su territorio a las escalas macro: del Distrito Federal, del Área Metropolitana y de la Región Geoeconómica. En este artículo se busca describir, de forma resumida, los diversos planes y proyectos de organización territorial que, desde entonces, se formulan para el Distrito Federal y su entorno. 
PALABRAS CLAVE: Brasilia; Planificación Territorial; Proyectos Urbanos

Na esteira do ufanismo nacional-desenvolvimentista que permeia o país a partir do pós-guerra (o Plano Salte, no Governo Dutra), mais intensamente, na segunda metade dos anos 1950 (o Plano de Metas, no Governo Juscelino) - e até mesmo de um certo misticismo (o sonho de Dom Bosco), a construção da nova capital do Brasil, Brasília, no Planalto Central, passados mais de cinquenta anos de sua inauguração, ainda tem presença marcante na agenda das investigações acadêmicas e dos debates profissionais nas mais diversas áreas do conhecimento. Destaque para as formulações referentes à sua organização territorial - desde a configuração urbanística original de Lucio Costa para o Plano Piloto até as suas articulações macrorregionais, passando pela emergente (e bastante problematizada) escala metropolitana.

Esse interesse por Brasília se deve não só à importância da matriz morfológicafuncional do seu plano urbanístico - calcada no movimento modernista europeu, como também, e principalmente, dos propósitos ideológicos e humanistas que, explicita ou implicitamente, estão associados a esse movimento e que, até hoje, são debitados na conta da Capital Federal, ignorando-se, assim, o fato que aquela Brasília, projetada em 1957, não mais existe em sua funcionalidade e configuração originais. Hoje, como a terceira metrópole brasileira em população, existe de fato uma outra Brasília - real, multifacetada e em acelerado processo de conurbação, e que, espacial e sociologicamente, extrapola as fronteiras do seu Plano Piloto original. "É essa Brasília real que vem exigindo uma abordagem de planejamento urbano que transcenda a lógica da racionalização da [sua] dinâmica urbana que - de alguma maneira, é corolária da sua própria concepção urbanística - e contemple uma realidade multifacetada e complexa” (Medeiros e Campos, 2010).

Pensada desde sempre como importante instrumento para a operacionalização do ideário de vários movimentos da geopolítica nacional desde a Inconfidência Mineira, mais precisamente após a Marcha para o Oeste, na primeira metade do Século XX, a mudança da capital para o Planalto Central brasileiro - relevante para o Revista Eletrônica: Tempo - Técnica - Território, V.7, N.2 (2017), 1:17 ISSN: 2177-4366 
desenvolvimento nacional - não se fez acompanhar de alguma intensão de planejamento territorial. O próprio Lucio Costa, atendo-se estritamente ao edital do Concurso para Plano Piloto, afirma no seu Relatório que “Brasília não será uma decorrência do planejamento regional, mas a causa dele; a sua fundação é que dará ensejo ao ulterior desenvolvimento planejado da região.” O que realmente só começa a acontecer, a partir da metade dos anos 1970 (Costa, 1957; Farret, 2015).

Por tudo isso e com o peso de ser um projeto modernista, Patrimônio da Humanidade e com elevado crescimento populacional, Brasília, hoje, enfrenta a emergência de novos problemas socioterritoriais, cujas origens e soluções extrapolam os limites daquela Brasília contida no plano urbanístico de Lucio Costa e que estão a exigir novas arquiteturas técnicas e institucionais. Mais importante, Brasília enfrenta o desafio de ter a sua dinâmica territorial conciliada - mas não exclusivamente focada - com a preservação do seu plano urbanístico original. Tão ou mais relevante nessas arquiteturas é a necessidade de incorporar as demandas de uma população que cresce a taxas ainda elevadas, tanto nas comunidades locais (cidades satélites/bairros), como nas metropolitanas (Entorno) e regionais (Região Geoeconômica).

De forma errática, ações de planejamento nesta direção têm sido empreendidas desde meados dos anos 1970. Sem a pretensão de esgotar o tema, propõese, neste texto, apresentar uma breve descrição das inúmeras propostas de planejamento que, ao longo dos últimos 50 anos, buscam atender a esses desafios socioterritoriais da capital federal.

\section{Os Planos Territoriais para Brasília: um longo e tortuoso percurso}

O planejamento territorial do Distrito Federal, em todas as suas escalas, tem ocorrido de forma pontual e sistemática ao longo de seus mais de 50 anos de existência. Nunca houve um pano de fundo que, respeitado e acreditado, pudesse balizar as ações dos sucessivos governos da capital federal. Ressalte-se que, desde antes da inauguração de Brasília, em 1960, o próprio plano urbanístico de Lúcio Costa já sofre alterações, visando adequá-lo não só às condições do ambiente físico, como, na sequência, às pressões sociais e políticas, refletindo demandas legítimas e interesses nem tanto. 
Essas ações de planejamento podem ser identificadas com três momentos da evolução da cidade: (i) aquelas sugeridas pelo júri do concurso de urbanismo para o plano piloto de Brasília, portanto, antes do início da sua implantação, (ii) aquelas ocorridas durante as obras de implantação e depois da inauguração, por decisão tanto da Novacap (Companhia Urbanizadora da Nova Capital) como da equipe de Lucio Costa e, finalmente, (iii) aquelas que emergem a partir da década de 1970, quando a cidade começa a assumir funções que extrapolam o seu papel de capital federal.

Enquanto as primeiras manifestações de planejamento ocorrem à escala intraurbana, o contínuo crescimento demográfico, potencializado a partir dos anos 1970 - com mais intensidade na década de 1990 - faz com que Brasília extravase a sua concepção original de cidade capital para emergir como centro de uma área metropolitana que engloba mais de vinte municípios pertencentes aos estados de Goiás e Minas Gerais. Com corolário natural desse processo, os problemas urbanos são amplificados, tornando-se mais complexos e demandando novos paradigmas e escalas de planejamento.

Cabe ressaltar que, já nas primeiras décadas da nova capital, planos foram elaborados, sem, contudo, apresentarem uma abrangência territorial mais ampla, focados que estavam, quase exclusivamente, na proteção ao plano urbanístico do Plano Piloto, que, desde sempre, sofre pressões em relação às suas premissas ideológicas, sociológicas e ambientais, à sua integridade original, enfim. Não raras vezes os planos são formulados para legitimar/acomodar ações de natureza espacial irregulares, reforçando a velha história do cachorro correndo atrás do rabo! De forma resumida, descreve-se a seguir esses planos.

\section{PLANIDRO: urbanismo sanitarista e segregação planejada}

Desde o anúncio da construção de Brasília, desencadeia-se um amplo movimento migratório para a cidade. Esse crescimento populacional induz a um intenso processo de urbanização que supera, em muito, as expectativas iniciais dos planejadores.

Na segunda metade da década de 1950, com a cidade em implantação, e principalmente na de 1960, com a cidade já inaugurada, essa população de imigrantes, a Revista Eletrônica: Tempo - Técnica - Território, V.7, N.2 (2017), 1:17 ISSN: 2177-4366 
maioria de baixa renda, se estabelece em canteiros de obras e em invasões, enquanto que segmentos de renda média, em menor escala, acomodam-se em moradias funcionais, construídas pelo setor público (Fundação da Casa Popular e autarquias da previdência social). Para fazer frente a essa ocupação rápida e desordenada, são construídas as primeiras cidades satélites, tanto por expansão de assentamentos existentes (Planaltina, Brazlândia) como pela criação de novos assentamentos (Núcleo Bandeirante, Taguatinga, Sobradinho, Gama, Guará, Ceilândia). Ressalte-se que, a implantação dessas cidades, situadas a uma distância média de trinta quilômetros do Plano Piloto, contraria a recomendação (previsão?) contida no Relatório de Lucio Costa: “só deveria ocorrer após a completude do Plano Piloto”.

A remoção dessa população e a localização desses assentamentos, em sua quase totalidade, são preconizadas, nos anos 60, pelo Plano Diretor de Água, Esgoto e Controle da Poluição - Planidro, nome emprestado da empresa responsável por sua elaboração - plano este que recomenda a adoção de um limiar populacional para a bacia do lago Paranoá. Essa estratégia, que visa a favorecer a preservação do entorno do Plano Piloto e, por extensão do lago, é justificada pela ideologia do urbanismo sanitarista, dando início ao processo que Campos chama de "segregação planejada” ( Campos, 1988).

Estava, assim, configurado um padrão polinucleado de ocupação do território do Distrito Federal, caracterizado por aglomerações dispersas, baixas densidades residenciais, forte apartação social e espacial e elevados custos de infraestrutura, incluindo o transporte urbano.

\section{PEOT: antecipando-se ao caos urbano}

Nos anos 1970, o Governo Federal (lembrando que o DF, até a Constituição de 1988, tem seu prefeito indicado pelo Presidente da República), no limiar de a cidade atingir uma população de um milhão de habitantes e sua mancha urbana já começando a extrapolar a divisa do Distrito Federal com Goiás, bem como os graves problemas de infraestrutura de saneamento e transporte, mediante convênio, literalmente interveio no planejamento territorial da Capital Federal, para o que foi dedicado um tópico no II Plano Nacional de Desenvolvimento (II PND). Tudo com o objetivo de reverter o já 
incipiente processo de degradação socioespacial do Distrito Federal, principalmente nas áreas urbanas.

Para isso, Grupo de Trabalho constituído por técnicos do Governo do Distrito Federal, Ipea e Ministério Interior, trabalha em duas escalas: a regional, elaborando o PERGEB - Plano Estratégico da Região Geoeconômica de Brasília, e a urbano-distrital, elaborando o PEOT- Plano Estrutural de Organização Territorial.

Enquanto o PERGEB não passa da esfera das intenções, o PEOT, focado na infraestrutura urbana de saneamento e transportes, tem dois objetivos, de certa forma, contraditórios: por um lado, a preservação da bacia do lago Paranoá para o abastecimento de água, o que implica na interdição de novas ocupações na área; e, por outro lado, a diminuição dos custos e tempos de deslocamento da população, o que exigiria uma estrutura urbana mais compacta do que aquela apresentada pelo padrão polinucleado.

A visão sanitarista predomina e o PEOT propõe um vetor de expansão urbana, afastado da bacia do lago: ao longo da BR-040, no quadrante sudoeste do Distrito Federal. Hoje, conurbado com o território goiano, esse vetor abriga a área de maior crescimento urbano na região.

Tendo em vista o instituto da propriedade pública das terras do Distrito Federal e, portanto, um maior poder de controle sobre o uso e ocupação do solo, o fato é que Brasília “exporta” para Goiás (onde a legislação e os controles urbanísticos eram - e são - bem mais flexíveis), o ônus dessa expansão urbana, sobrecarregando um sistema de transporte urbano já deficiente.

\section{Brasília Revisitada: esquecer a visão sanitarista}

Os anos 1980 evidenciam uma peculiaridade na urbanização do Distrito Federal: a acentuada elevação do custo do solo e dos aluguéis, não só no Plano Piloto, mas até mesmo em algumas cidades satélites, bem como o fim do Banco Nacional da Habitação (BNH), provocam uma alta demanda reprimida no acesso à moradia também para as classes baixa e média da população. 
Como decorrência, surge um sem número de parcelamentos irregulares em terras públicas e privadas, graças à ainda hoje confusa situação fundiária do Distrito Federal. Promovidos por empreendedores privados, esses parcelamentos dão origem aos condomínios irregulares, alguns com moradias de alto padrão e todos implantados à margem da regularidade fundiária e da legislação urbanística. Esses assentamentos, hoje, ocupam 40\% da mancha urbana do Distrito Federal e abrigam uma população de mais de 500 mil habitantes, constituindo um grande gargalo jurídico-institucional ao ordenamento territorial da capital federal.

Em 1987, sob a pressão desse padrão crescente de ocupação irregular e descontrolada, o próprio Lucio Costa iria deixar de lado o ideário da “não-ocupação” da bacia do Paranoá, elaborando o plano Brasília Revisitada, no qual propõe a construção de “quadras proletárias” ao longo dos principais eixos viários de acesso ao Plano Piloto (a única implantada foi o Setor Lucio Costa, entre Taguatinga e o Plano Piloto) e a regularização/construção de novos bairros residenciais para as classes médias, adjacentes ao Plano Piloto: a Vila Planalto (após o seu tombamento e legalização); o Setor Octogonal, o Setor Sudoeste e o Setor Noroeste.

\section{PDOT: descentralização e a formação da jovem metrópole}

Por força da Lei Orgânica do Distrito Federal, em 1997, é elaborado o primeiro PDOT- Plano Diretor de Ordenamento Territorial (PDOT-1), com a responsabilidade de promover o planejamento integral do Distrito Federal à escala macro. Para a escala micro - a dos bairros/cidades satélites-, seriam elaborados os Planos Diretores Locais (PDL) com o objetivo de identificar medidas de desenvolvimento econômico e social e de uso e ocupação do solo. Ao fim, só cinco cidades satélites tiveram seus PDL aprovados: Sobradinho, Candangolândia, Taguatinga, Samambaia e Ceilândia.

O PDOT-1 é marcado por duas ações com fortes impactos na estrutura espacial do Distrito Federal. A primeira, a busca da descentralização das atividades econômicas, então altamente concentradas no Plano Piloto. Para isso são propostas: (i) a criação de novas cidades satélites (São Sebastião, Samambaia, Santa Maria, Recanto das Emas, Riacho Fundo e a mais importante de todas, Águas Claras), algumas resultantes de programas de erradicação de invasões e tendo a doação de lotes semi-urbanizados, com nítido teor populista-eleitoral, como a sua marca registrada. Dá sequência à política de 
ocupação dos vazios urbanos adjacentes aos assentamentos infraestruturados, estratégia basilar do PEOT dos anos 70. Nesse sentido, por exemplo, Águas Claras é concebida como uma cidade linear, instrumental para a viabilização econômica do metrô; (ii) a criação de novas centralidades urbanas, das quais a mais importante foi a construção do novo Centro Administrativo do Governo do Distrito Federal, localizado entre Taguatinga e Ceilândia; e (iii) a densificação das cidades existentes, por meio de uma ocupação verticalizada.

\section{Novo Quadro Urbano e Nova Arquitetura Institucional do Distrito Federal}

Mais recentemente, a partir da década de 1990, mais intensamente na primeira década deste milênio, além dos problemas socioespaciais já acumulados, novos problemas e novas configurações institucionais surgem, passando a exigir novos paradigmas para o planejamento desta Brasília que, há muito, já extravasa os limites funcionais de ser exclusivamente uma capital federal. São eles:

\section{Metropolização não-institucionalizada}

O crescimento populacional do Distrito Federal, nos anos 2000, mostra uma intensificação dos fluxos migratórios para a região do Entorno. A taxa de crescimento populacional, apesar de decrescente, é ainda elevada, superior à média nacional e das demais metrópoles brasileiras. Esse fator, associado ao tombamento do Plano Piloto, gera a elevação dos preços imobiliários no Distrito Federal como um todo, hoje um dos mais altos do País. Com isso, tanto os migrantes recém-chegados de outros estados, como moradores do Distrito Federal, premidos pela alta dos preços residenciais, fixam residência na região do Entorno, criando um intenso movimento pendular casa-trabalho. Consolida-se, assim, a região metropolitana de Brasília, tendo a Capital Federal como polo dominante, em termos de renda, oferta de empregos, PIB, IDH etc.

A região metropolitana de Brasília, oficialmente denominada RIDE - Região Integrada de Desenvolvimento do DF e Entorno, abrange um conjunto de 22 municípios de três entes federativos: Distrito Federal, Goiás e Minas Gerais, uma população de 3,5 milhões de habitantes (a terceira do País, em tamanho) e uma taxa de crescimento demográfico médio de 3,4\% ao ano. 
Os impasses para o planejamento metropolitano - recorrente no País e, em Brasília agravados pelos obstáculos político-institucionais decorrentes do envolvimento de municipalidades pertencentes a três unidades distintas da federação, deixam o Distrito Federal com o ônus de criar a infraestrutura (transporte, educação e saúde) para, em grande parte, atender a uma população “estrangeira” ao seu território, de certa forma, substituindo o órgão metropolitano.

\section{Desarticulação regional}

Desde a tentativa de implantar o PERGEB, em meados da década de 1970, não há plano de estruturação para a região, apesar da existência de um órgão criado para tal finalidade, a SUDECO, vinculada ao Ministério da Integração. Com isso, o Distrito Federal continua a desempenhar dois papeis: um negativo, funcionando como o grande centro dos serviços primários de saúde da região, sobrecarregando a sua rede pública; e outro positivo, drenando para si boa parte da poupança e renda do consumo da região para o seu mercado.

\section{Mobilidade metropolitana}

O grande fluxo pendular entre o Entorno e o Distrito Federal, particularmente o seu Plano Piloto, sobrecarrega o sistema viário da Capital, exigindo, cada vez mais, obras de envergadura (duplicação de vias, construção de viadutos etc), drenando recursos que poderiam ser usados em obras/serviços de interesse específico do Distrito Federal. Além disso, a fragilidade nos controles operacionais do sistema de transporte urbano metropolitano repercute na mobilidade e produtividade da mão de obra empregada no Distrito Federal.

\section{Desordem fundiária}

Dentre os grandes problemas que desafiam o planejamento do Distrito Federal, talvez o mais grave de todos reside na desordem fundiária, envolvendo tanto a definição de titularidades da terras urbana e rural como o uso e ocupação do solo à margem das normas urbanísticas vigentes. Um problema que se arrasta há anos nas esferas administrativa e judiciária. Hoje, a Terracap, agência de desenvolvimento do Governo do Distrito Federal, é dona de 64\% das terras do DF, enquanto que particulares detém 24\% e a União os restantes $12 \%$. 
Uma das questões mais críticas no DF, a ocupação irregular do solo, tem como pano de fundo a incompletude do processo de desapropriação das terras para a construção da capital federal, antes, portanto, da inauguração da cidade, em 1960. O açodamento no procedimento expropriatório adotado no processo de mudança da capital para Brasília, a imprecisão nos registros paroquiais originados nos municípios onde estavam registradas as fazendas que hoje compõem o território do Distrito Federal, a evolução demográfica nas últimas décadas e a evolução no preço da terra urbana são elementos que ampliam o processo de ocupação irregular de seu território, dessa forma incrementando a ocorrência de uma intensa desordem fundiária que, não raras vezes, resulta em conflitos sociais.

Ressalte-se que, ao longo da década de 1960, o Governo Federal prossegue com o processo de desapropriação dos imóveis particulares no Distrito Federal. No entanto, o período é marcado por uma aguda restrição orçamentária por parte do governo central, que, somada à descontinuidade institucional, acaba implicando na diminuição do ritmo de desapropriações realizadas, situação que perdura pelas décadas seguintes, arrefecendo o projeto de tornar efetivamente públicas todas as terras do Distrito Federal.

Para se ter uma ideia do problema, a situação fundiária do Distrito Federal compreende terras em situação jurídica as mais diversas; mais especificamente:

- $\quad$ Terras Devolutas - terras cuja propriedade é desconhecida, não abrangidas por domínio particular por qualquer título legítimo e que não foram objeto de ação discriminatória.

- Terras Públicas - agregadas ao patrimônio público por desapropriação ou doação; entre as terras públicas, há terras de propriedade da Terracap, da União Federal e Distrito Federal.

- $\quad$ Terras Particulares - registradas em Cartório de Registro de Imóveis do DF em nome de particulares.

- Terras Públicas e Particulares em Regime de Propriedade Comum adquiridas pela Terracap - consideradas terras nas quais o Poder Público desapropriou determinado percentual da gleba, sem definir claramente os limites da propriedade pública ou privada. 
O cenário propício para a expansão urbana desordenada fica especialmente completo ante a incapacidade de o governo do Distrito Federal suprir a demanda por habitação destinada à classe média, acabando por incentivar a comercialização irregular de lotes em terras de titularidade controversa. Essa desordem fundiária atinge, hoje, diversas áreas do Distrito Federal - desde áreas nobres a áreas de baixa renda contando-se mais de quinhentos assentamentos oficialmente cadastrados (80\% em áreas urbanas) e envolvendo uma população de mais de 500 mil habitantes.

Brasília é, talvez, a única cidade brasileira com condomínios irregulares de alto luxo (moradias com áreas superiores a 500m², garagens para três/quatro carros, piscinas etc). O curioso é que, apesar de irregulares, o IPTU é cobrado regularmente dessas propriedades. Há um lento e complicado processo de regularização, envolvendo o Poder Executivo (em alguns momentos, chegou a haver uma secretaria só para cuidar do assunto), o Ministério Público e o Poder Legislativo.

\section{Novo status institucional: cidade tombada e autonomia política}

No final da década de 1980, dois eventos dão nova roupagem institucional a Brasília, trazendo consigo novos desafios para o planejamento e a gestão da capital federal: o seu tombamento pelo Instituto do Patrimônio Histórico e Artístico Nacional (IPHAN) e a sua promoção como ente federativo autônomo, no mesmo patamar dos estados da federação.

Além disso, em 1987, Brasília é listada pela Unesco como Patrimônio Cultural da Humanidade e, em 1988, pela nova Constituição, o Distrito Federal adquire autonomia política, com poderes executivo e legislativo constituídos por representantes eleitos, com atribuições para legislar sobre uso e ocupação do solo; na sequência, em 1990, o Plano Piloto é tombado pelo IPHAN, tornando-se o primeiro conjunto urbano do século 20 a obter tal distinção. Em relação a este fato, há dois momentos que devem ser lembrados. O primeiro é a chamada Lei Santiago Dantas, de 14 de abril de 1960, antes portanto da inauguração da cidade, pela qual “qualquer alteração no plano piloto de Brasília dependeria de lei federal, portanto do crivo do Congresso.” O segundo, a iniciativa do Presidente Kubitchek de solicitar ao então Serviço de Patrimônio Histórico 
Nacional, o atual IPHAN, que estudasse a possibilidade do tombamento de Brasília como patrimônio histórico.

A questão do tombamento, ao mesmo tempo que representa uma solução às ameaças que o plano urbanístico de Brasília vinha (e vem ainda) sofrendo, não deixa de trazer alguns impactos não desejados. Nesse sentido, o esforço do Governo do Distrito Federal junto à Unesco (à época do mandato do governador José Aparecido, o primeiro após a democratização do País, na presidência de José Sarney) para viabilizar a inclusão da cidade como Patrimônio da Humanidade, e a velocidade com que isso é feito, decorre menos de um interesse cultural e mais de uma estratégia para salvaguardar o plano urbanístico de Lúcio Costa e a arquitetura de Niemeyer, principalmente o primeiro. Desde há muitos anos, há manifestações, nem sempre visíveis, do mercado imobiliário visando ao adensamento do Plano Piloto, com o argumento, velado e nada sutil, de reduzir os elevados custos de manutenção de suas áreas verdes!

Em paralelo, uma segunda vertente propõe a expansão do Plano Piloto, com o argumento de que a morfologia urbanística da cidade - tendo como modelo a cidade linear - poderia ser expandida em suas extremidades, de modo a satisfazer uma demanda residencial reprimida, oriunda de segmentos de classe média que, de outra forma, continuariam a alimentar a oferta dos chamados condomínios irregulares. Ressalte-se que essas pressões, já nos anos 1980, antes da decisão da Unesco, são responsáveis pela elaboração, por parte de Lucio Costa, do plano Brasília Revisitada.

Nesse sentido, a condição de patrimônio nacional e internacional faz com que Brasília esteja sujeita a um marco regulatório mais rigoroso, que transcende e reforça os tradicionais normativos de uso e ocupação do solo e de edificações. Ressalte-se que, para muitos agentes sociais, na sua escala urbanística, o marco regulatório do tombamento ainda é pouco inteligível, uma vez que o que o seu objeto são as escalas de Brasília - a monumental/Eixo Monumental; a cotidiana/Unidades de Vizinhança; a gregária/ Área Central; e a bucólica/a paisagem natural das áreas não edificadas [o Cerrado, o céu, o lago] - o que escapa à percepção de boa parte da população. Com isso, o tombamento constitui-se em fonte de acalorados debates de natureza técnica e política, em torno de seus impactos positivos e negativos. A cidade vive sob duas correntes preservacionistas que, como observa Lucio Costa, “...uma daqueles que Revista Eletrônica: Tempo - Técnica - Território, V.7, N.2 (2017), 1:17 ISSN: 2177-4366 
acham o Plano Piloto intocável; e outra daqueles que, pelo contrário, entendem que a vida continua e que a cidade tem de ser reformulada de acordo com as novas necessidades.” (conforme citação de documento do IPHAN-DF, em maio de 2016).

No primeiro caso, como fato positivo, destaca-se, inegavelmente, o meritório resultado até hoje alcançado da preservação deste projeto único do mundo. No segundo caso, como impacto negativo, pode-se citar a criação de um patamar de preços imobiliários monopolizados, dada a ausência de alternativas urbanísticas suficientes e equivalentes e, quem sabe o mais importante, a promoção do fechamento da área tombada, com o Estado criando uma “elitização planejada e oficial”. Em outras palavras, o tombamento gera um substancial incremento no patamar do valor de troca dos imóveis da área.

Além disso, essa falta de consenso sobre o alcance do tombamento leva a medidas esdrúxulas, como, por exemplo, o veto a intervenções necessárias à melhoria da vida cotidiana da população, como é o caso da transformação do Eixo Residencial (o Eixão, hoje uma autêntica via expressa cortando o Plano Piloto) em uma aprazível avenida urbana.

\section{O Planejamento Estratégico, Hoje: intervenções urbanísticas pontuais}

Na sequência das ações de planejamento do Distrito Federal, enquanto no plano local o PDOT-2 (revisão decenal obrigatória do PDOT-1), aprovado em 2009, encontrase sub judice, em virtude de controversos artigos que regulam o uso e ocupação do solo e questões ambientais, à escala metropolitana, pela ausência de um sólido arcabouço institucional, os resultados são ainda menos animadores.

A partir da década de 2000, numa guinada na estratégia de planejamento até então adotada, o governo do Distrito Federal promove a formulação de grandes planos e projetos urbanos, basicamente visando à criação de novas centralidades urbanas. O planejamento territorial passa a ser focado, principalmente, embora não exclusivamente, em intervenções urbanísticas pontuais que, em tese, potencializariam a revitalização do espaço urbano, muitas em regime de parceria público-privada. Trata-se de uma estratégia, hoje, largamente aplicada em diversos países: os projetos Docklands/Londres, Puerto Madero/Buenos Aires e, no Brasil, os projetos Operação 
Urbana Largo do Batata/São Paulo; Porto Maravilha/Rio de Janeiro e o Cais do Guaíba/Porto Alegre, este último ainda em fase de estudos de viabilidade.

Nessa linha, duas grandes ações de planejamento são elaboradas para Brasília, caracterizando um quadro que poderíamos chamar de esquizofrenia urbanística, uma vez que, de um lado, há o PDOT que preconiza um planejamento integrado do território, sob a égide participativa do Estatuto da Cidade, e, de outro lado, simultaneamente, contrata-se o escritório Jaime Lerner para elaborar o Projeto Básico de Desenvolvimento Urbano e a Jurong Consultoria, empresa pública de Cingapura, para elaborar o plano Brasília, Cidade Mundial. Ambos convergem para um elenco de intervenções urbanas pontuais, a saber:

- Ampliação do sistema de transporte de massa

- Elaboração do plano Brasília, Cidade Mundial

- Construção do Novo Centro Administrativo do GDF

- Plano urbanístico do Eixo Avenida Interbairros

- $\quad$ Cidade Digital

O plano de ampliação do sistema de transporte de massa para o Distrito Federal compreende a extensão da rede de metrô e a implantação de um sistema de VLP veículo leve sobre pneus. O plano Brasília, Cidade Mundial, elaborado pela Jurong Consultoria, empresa pública de Cingapura, visa a colocar a Capital no circuito das cidades globalmente competitivas, por meio de quatro projetos-polos estratégicos:

- Centro Financeiro Internacional

- Cidade Logística (Aerotrópolis): aeroporto para cargas, depósitos, conveniências para caminhões/caminhoneiros

- Cidade Industrial JK: ampliação do Polo Industrial JK na fronteira do DF com a região do Entorno

- Trem Urbano de Alta Velocidade (TAV): ligando os quatro projetospolos de atividade (Aerotrópolis - Aeroporto Internacional - Centro Financeiro - Cidade Industrial) com as cidades goianas de Anápolis e Goiânia 
Cada projeto-polo propõe a criação de microcidades com uma função âncora, onde seriam instalados diversos tipos de comércio e serviços, inclusive residenciais.

O novo Centro Administrativo do GDF, a $30 \mathrm{~km}$ do Plano Piloto e implantado mediante parceria público-privada, consiste em um complexo edilício (incluindo centro de convenções, hotéis) onde cerca de 15 mil funcionários exercerão suas atividades. Trata-se de uma estratégia de descentralização que visa à criação de uma nova centralidade urbana, pelo efeito multiplicador que o Centro desencadeará na área, além de reflexos positivos na mobilidade urbana no Plano Piloto.

O Eixo Avenida Interbairros, projeto urbano elaborado pelo escritório Jaime Lerner, mais do que um eixo viário, consiste num corredor de transporte e atividades econômicas, para o qual serão direcionados equipamentos públicos e atividades terciárias privadas. O Eixo abrigará quatro novas centralidades urbanas, com polos de atividades de comércio, serviços e moradias, cruzando áreas com populações de rendas média e alta (Guará, Mansões Parkway, Águas Claras, Taguatinga e Ceilândia).

A Cidade Digital, em implantação, constitui-se de um complexo de serviços ligados à tecnologia da informação, como por exemplo, o Data Center do Banco do Brasil, ora em construção, e que, em sinergia com a Cidade Logística (Aerotrópolis), busca tornar a cidade economicamente mais visível e competitiva numa escala mundial.

Como se observa, os movimentos atuais do planejamento territorial do Distrito Federal buscam dotar a Capital Federal de infraestruturas capazes de torná-la um centro econômico de peso, contrariamente à direção propugnada pelos seguidores da manutenção de sua concepção original. Estes preconizam o fortalecimento - e até mesmo a exclusividade de seu papel de civitas, a capital político-administrativa do País -, cabendo a outras cidades da região as funções de polarização econômica.

Ainda, para completar o nebuloso quadro do planejamento territorial do Distrito Federal, está em fase final de elaboração o ZEEDF- Zoneamento Econômico-Ecológico do Distrito Federal, um plano previsto na Lei Orgânica do Distrito Federal que, em 
tese, deveria balizar todos os planos de ordenamento territorial do Distrito Federal (GDF, 2013). Não é o que acontece: ainda em elaboração desde 2010, mesmo assim por pressão legal do Ministério Público do Distrito Federal, o ZEE é ignorado pelos diversos planos que, pela lógica, deveriam sucedê-lo. Mais uma vez, a história do cachorro correndo atrás do rabo!

\section{Bibliografia}

CAMPOS, N. L. A Produção da Segregação Residencial em Cidade Planejada. Dissertação (Mestrado em Planejamento Urbano), FAU, Universidade de Brasília, Brasília: 1988.

COSTA, L. Relatório do Plano Piloto de Brasília. Rio de Janeiro: Novacap, 1957.

FARRET, R. Urbanismo em Brasília: Fundamentos, Intencionalidades e Resultados. Monografia (a ser publicada em livro), Brasília: 2016.

FICHER, S. et al. Brasília: Uma História de Planejamento. Brasília: FAU/UnB, 2006.

GDF/SEDU. Zoneamento Ecológico-Econômico do Distrito Federal. Brasília: Greentec-Sedu, 2013. (versão preliminar)

MALAGUTTI, C. Loteamentos clandestinos no DF: legalização ou exclusão? Brasília, Universidade de Brasília, dissertação (Mestrado em Planejamento Urbano), FAU, Universidade de Brasília, 1996. Fernando

MEDEIROS, A. E.; CAMPOS, N. L. Cidade projetada, construída, tombada e vivenciada: pensando o planejamento urbano em Brasília. In PAVIANI, A. ET AL (org), Brasília 50 Anos: da capital à metrópole. Brasília: Editora UnB, 2010. 